\title{
BMJ Open Propensity-matched study of enhanced primary care on contact with the criminal justice system among individuals recently released from prison to New Haven
}

\author{
Emily A Wang, ${ }^{1}$ Hsiu-ju Lin, ${ }^{2,3}$ Jenerius A Aminawung, ${ }^{1}$ Susan H Busch, ${ }^{4}$ \\ Colleen Gallagher, ${ }^{5}$ Kathleen Maurer, ${ }^{5}$ Lisa Puglisi, ${ }^{1}$ Shira Shavit, ${ }^{6}$ Linda Frisman ${ }^{2,3}$
}

To cite: Wang EA, Lin $\mathrm{H}$, Aminawung JA, et al. Propensity-matched study of enhanced primary care on contact with the criminal justice system among individuals recently released from prison to New Haven. BMJ Open 2019;9:e028097. doi:10.1136/ bmjopen-2018-028097

- Prepublication history for this paper is available online. To view these files, please visit the journal online (http://dx.doi. org/10.1136/bmjopen-2018028097).

Received 21 November 2018 Revised 15 January 2019 Accepted 4 March 2019

Check for updates

(C) Author(s) (or their employer(s)) 2019. Re-use permitted under CC BY-NC. No commercial re-use. See rights and permissions. Published by BMJ.

For numbered affiliations see end of article.

Correspondence to Professor Emily A Wang; emily.wang@yale.edu

\section{ABSTRACT}

Background Health systems can be integral to addressing population health, including persons with incarceration exposure. Few studies have comprehensively integrated state-wide data to assess how the primary care system can impact criminal justice outcomes. We examined whether enhanced primary care can decrease future contact with the criminal justice system among individuals just released from prison.

Methods We linked administrative data (2013-2016) of Connecticut Department of Correction, Department of Mental Health and Addiction Services, Department of Social Service, Court Support Services Division, and Department of Public Health to conduct a quasiexperimental study using propensity score matching of 94 participants who received enhanced primary care in Transitions Clinic to 94 controls not exposed to the programme. The propensity score included 23 variables, which encompassed participants' medical and incarceration history and service utilisation. The main outcomes were reincarceration rates and days incarcerated in the first year from the index date, which was either enrolment in the Transitions Clinic programme or release from prison in the control group.

Results The odds of reincarceration, including arrests and new convictions, were similar for the two groups, but Transitions Clinic participants had lower odds of returning to prison for a parole or probation technical violation (adjusted OR: 0.38; 95\% Cl 0.16 to 0.93 ) compared with the control group. Further, Transitions Clinic participants had fewer incarceration days (incidence rate ratio: 0.55; $95 \% \mathrm{Cl} 0.35$ to 0.84 ) compared with the control group. Conclusions Enhanced primary care for individuals just released from prison can reduce reincarceration for technical violations and shorten time spent within correctional facilities. This study shows how community health systems may play a role in current strategies to reduce prison populations.

\section{INTRODUCTION}

Over 20 million individuals living in the USA have a history of imprisonment. ${ }^{1}$ Incarcerated

\section{Strengths and limitations of this study}

- This is one of the first studies evaluating the efficacy of a primary care-based intervention on future criminal justice system contact, including arrest, reincarceration and length of time incarcerated.

- The study uses comprehensive correctional system administrative data, inclusive of jails and prisons, and data on probation and parole.

- The study merges administrative data from an integrated correctional system, community corrections, state-sponsored insurance for individuals of low socioeconomic status, state-sponsored mental health and substance use treatment, and death indices to provide for robust construction of propensity score and measurement of primary outcomes.

- Causal associations are limited by use of propensity score methodology as opposed to experimental randomisation of treatment.

- Choice of variables used in the construction of the propensity scores does not include individual characteristics like housing status and social support, or individual symptomatology like depression, nor the characteristics of communities to which people return.

persons have worse health compared with the general population, with higher rates of chronic diseases and a high risk of hospitalisation and death immediately following release. ${ }^{2}$ Reasons for these health disparities likely include the extreme conditions of incarceration, trauma, social isolation, poverty, as well as the systematic barriers to obtaining employment, housing, food and healthcare following release. ${ }^{3-6}$ An astounding $66 \%$ of those released from prison will be reincarcerated within 5 years. ${ }^{7}$ Cycling in and out of prison is among the least healthy exposures in this population and traditionally has not been addressed in the primary care setting. ${ }^{89}$ 
While repeated contact with the criminal justice system is in large part driven by police, prosecutorial and judicial practices, individuals' health may contribute to our country's high rates of repeated imprisonment. Untreated substance use and mental illness are associated with repeated incarceration, or recidivism, ${ }^{10-12}$ with the correlated argument that the lack of primary care and behavioural healthcare may also contribute to our nation's unparalleled recidivism rate. Before the passage of the Affordable Care Act, most individuals with a history of incarceration were either uninsured at release or did not have the financial resources to pay for healthcare. ${ }^{13}$ The Medicaid expansion in 2014, which provided insurance and thus access to primary care and substance use and mental health treatment to justice-involved populations, was touted as an opportunity to potentially reduce recidivism and the costs of incarceration. ${ }^{14-16}$ Two recent articles have empirically demonstrated how Medicaid expansion is associated with decreased crime at the county level. ${ }^{17} 18$ But past randomised or quasi-experimental studies of linkage to primary care or primary care-based interventions have not found any effect on reducing future jail time of participants enrolled. ${ }^{19-23}$

To date, efforts to systematically address incarceration as a social determinant of health within the community health system are limited, although emerging in the USA and Australia. ${ }^{24}$ The Transitions Clinic Network (TCN) is the largest consortium of primary care clinics in the USA that aims to increase access to primary care services and improve health and well-being among high-risk, chronically ill people recently released from incarceration. ${ }^{25}$ We used data from a single programme of the TCN to examine whether enhanced primary care can decrease future contact with the criminal justice system among individuals with chronic medical conditions just released from prison.

\section{METHODS}

\section{Setting}

The TCN is a national consortium of 29 primary care centres that serves the health needs of individuals returning from incarceration. ${ }^{25}$ The TCN programme is intended to provide primary care to anyone released from a correctional facility with a chronic health condition or is older than 50 years of age. Health conditions include physical health (hepatitis $\mathrm{C}$, hypertension, diabetes), mental health (depression, post-traumatic stress disorder, schizophrenia) or substance use disorders (opioid use disorder). Interdisciplinary teams are the crux of the TCN model, where community health workers with personal histories of incarceration are embedded within primary care teams to identify and support patients returning home from incarceration who are at risk for poor health outcomes. Community health workers interact with patients in and out of the clinic to address re-entry-related social determinants of health, such as housing, food access or employment, and link patients with community agencies. They use their personal experience of incarceration to educate the healthcare team about patients' challenges, facilitate patient-provider communication, and help patients navigate and build trust in the medical system. TCN programmes also address patients' behavioural health needs at each visit and make appropriate referrals to substance abuse and mental health treatment, as well as advocate on patients' behalf in interactions with the criminal justice system, especially courts, probation and parole when appropriate. For this study, we excluded individuals who already had a primary care provider (ie, already had established care in the community) or were moving out of the state. Individuals were referred to the TCN programme by the correctional system prior to discharge, from community service providers or identified through outreach of the community health workers. We assessed the impact of the TCN programme on criminal justice outcomes among patients released from the Connecticut Department of Correction (DOC) prison system who received primary care from May 2013 to February 2016 as part of a larger multisite cohort study funded by the Center for Medicare and Medicaid Innovation. Participants provided informed consent for this study, which is described elsewhere. ${ }^{25}$

\section{Study population}

We used propensity score matching ${ }^{26}$ to identify individuals who were comparable with TCN patients but were released from prison during the same period to an urban area similar to the one where the TCN programme was located. We matched participants by demographic, clinical and behavioural characteristics based on their likelihood of receiving care in the TCN programme. To obtain participant characteristics used in propensity matching, we linked administrative data from Connecticut DOC to data from Connecticut Medicaid and Department of Mental Health and Addiction Services (DMHAS). Identifiers used in the linkage included date of birth, first name, last name, social security number, gender and race/ethnicity. We used the Link King application, which employs both deterministic and probabilistic matching algorithms, to identify if the interagencies' records are from the same individual. ${ }^{27}$ We abstracted participants' demographics, criminal justice history and needs assessment scores from the DOC data; chronic medical conditions prior to their most recent incarceration through Medicaid service claims; and mental health and substance use treatment history from the DMHAS data.

From the linked data, we included the following variables in the logistic regression to estimate the propensity scores: participant demographics (eg, gender, race/ ethnicity and age at release), release year, DOC medical, mental health, substance use and criminal justice needs assessment scores (including violence, sentence length, discipline record and gang involvement), criminal justice involvement history (including having a felony record, the percentage of one's life interacting with the DOC), type of release (under supervision or end of sentence), 
mental health and substance abuse diagnosis and treatment history, including proportion of one's life as a client of DMHAS, having any chronic condition, total number of chronic conditions, having 1 of 17 medical conditions included in the Charlson Comorbidity Index, ${ }^{28}$ the weighted Charlson Comorbidity Index score, ${ }^{29}$ and three common chronic conditions among individuals with a history of incarceration, but not otherwise included in the comorbidity index score: other gastrointestinal symptoms, opioid use disorder and alcohol use disorder.

We then used a greedy matching algorithm to match TCN cases to controls, in which the TCN cases were ordered and sequentially matched to the nearest matching non-TCN cases, one at a time without replacement. ${ }^{30-32}$ We chose a 1:1 case-control match method rather than inverse weighting or stratification because it produced the most balanced distribution of covariates for our sample. ${ }^{31}$ The index date was the TCN enrolment date for TCN programme participants, and the first DOC release date during the study window, 2012-2015, for the control group. Our final study sample comprised 94 patients who received enhanced primary care in the TCN programme and 94 propensity-matched controls.

\section{Measures}

Our primary outcome of interest was reincarceration within 12 months from the index date, as imprisonment is both a disruption in healthcare, employment and family life, and a driver of societal costs. We also assessed metrics that affect changes in prison or jail populations, including arrests and length of stay in correctional facilities. ${ }^{33}$ Finally, we examined imprisonment due to new and technical violations (violations of the condition of parole or probation), which is a focus of many state criminal justice reform efforts. We ascertained these outcomes from the Connecticut DOC and Court Support Services Division administrative data.

The secondary outcomes of this study included preventable emergency department (ED) visits, hospitalisations and length of hospital stay, which we ascertained from Medicaid and DMHAS administrative data. We applied the Agency for Healthcare Research and Quality's Prevention Quality Indicators (PQI) to categorise the primary diagnoses into preventable ED visits and hospitalisations. PQIs are population-based measures that can be used with hospital administrative data to identify quality of care for 'ambulatory care-sensitive conditions', ones for which primary care can potentially prevent the need for hospitalisation or for which early intervention can prevent more severe disease. ${ }^{345}$ Primary and secondary outcomes were specified a priori of analyses.

\section{Statistical analysis}

The study aimed to include a total of at least 170 individuals: 36 individuals per group would provide approximately $95 \%$ power to detect a difference in the mean number of days incarcerated comparing the treatment and comparison group, assuming that individuals in the TCN programme would spend $50 \%$ less time incarcerated (effect size $=35$ days). Eighty-one individuals per group would provide $80 \%$ power to detect a $50 \%$ difference in the proportion of people who are convicted for new or technical violations between the treatment and comparison group.

We compared individuals who received services at TCN with the pool of potential controls using t-tests and $\chi^{2}$ analysis on sociodemographics, chronic conditions, criminal justice and mental health history, and again following identification of the propensity-matched sample to ensure a balance of covariates. We then compared criminal justice contact and preventable healthcare utilisation between the two groups using t-tests and $\chi^{2}$ analysis as appropriate. Next, we used logistic regression and zero-inflated negative binomial $(\mathrm{ZINB})^{36}$ regression models, depending on the distribution of the outcome variable, to evaluate reincarceration, arrests, incarceration days, preventable ED visits, hospitalisations and length of stay during the 12-month period following the index date. We elected to use the zero-inflated Poisson (ZIP) or ZINB models because our observed outcome data have excess zeros (ZIP) and exhibit an overdispersion distribution (ZINB). ${ }^{37}$ We adjusted for length of time in the hospital for the criminal justice outcomes and time incarcerated for the healthcare utilisation outcomes. We considered $p$ values of equal to or less than 0.05 statistically significant. All statistical analyses were performed using SAS V.9.4.

\section{Patient involvement}

Patient members of our TCN community advisory board, TCN community health workers and individuals with histories of incarceration were involved in developing the research question. They were not involved in planning the design and conduct of the study. We have iteratively shared the progress of this study and our results to our TCN advisory board, inclusive of patients and individuals with histories of incarceration. We plan to disseminate these findings more widely to study participants and patients of the TCN at large.

\section{RESULTS}

In the unmatched study population, TCN programme participants were older and more likely to be white compared with those in the comparison group. TCN programme participants were sicker, had higher individual medical, mental health and criminal justice composite needs scores, a higher prevalence of inpatient treatment for mental health conditions, and a higher prevalence of alcohol use disorder compared with the comparison group. After the match, the groups were balanced, except for one TCN case that could not be matched and was discarded from the analysis (table 1).

Table 2 shows contact with the criminal justice system and preventable healthcare utilisation within a year following index date for the TCN and the matched 
Table 1 Participant characteristics by study group: pre and post propensity score matching

\section{Prematch \\ $\mathrm{n}(\%)$ or mean $( \pm \mathrm{SD})$ \\ TCN ( $n=95) \quad$ Control $(n=2594)$}

Postmatch

n (\%) or mean $( \pm$ SD)

TCN $(n=94) \dagger \quad$ Control $(n=94)$

\begin{tabular}{|c|c|c|c|c|c|}
\hline \multicolumn{6}{|l|}{ Release year } \\
\hline 2012 & $1(1.1)$ & 465 (17.9) & $* * *$ & $1(1.1)$ & $0(0)$ \\
\hline 2013 & 30 (31.6) & $616(23.7)$ & & $29(30.1)$ & $23(24.5)$ \\
\hline 2014 & $61(64.2)$ & $841(32.4)$ & & $61(64.9)$ & $68(72.3)$ \\
\hline 2015 & $3(3.2)$ & $672(25.9)$ & & $3(3.2)$ & $3(3.2)$ \\
\hline Male & $76(80)$ & $2294(88.4)$ & $\star *$ & $76(80.9)$ & $75(79.8)$ \\
\hline \multicolumn{6}{|l|}{ Race/Ethnicity } \\
\hline White & $30(31.6)$ & $191(7.4)$ & $* * *$ & 29 (30.9) & $31(33.0)$ \\
\hline Black & $51(53.7)$ & $1271(49.0)$ & & $51(54.3)$ & $48(51.1)$ \\
\hline Hispanic & $14(14.7)$ & $1125(43.4)$ & & $14(14.9)$ & $15(16.0)$ \\
\hline Age (at release) & $42.6( \pm 10.3)$ & $37.53( \pm 10.5)$ & 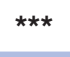 & $42.6( \pm 10.4)$ & $40.5( \pm 10.8)$ \\
\hline \multicolumn{6}{|l|}{ DOC assessment score } \\
\hline Mental health & $2.0( \pm 0.8)$ & $1.7( \pm 0.8)$ & $* \star \star$ & $2.0( \pm 0.8)$ & $2.1( \pm 0.9)$ \\
\hline Substance abuse & $3.4( \pm 1.2)$ & $3.0( \pm 1.3)$ & $* * *$ & $3.4( \pm 1.2)$ & $3.4( \pm 1.2)$ \\
\hline Education & $2.4( \pm 0.8)$ & $2.7( \pm 0.9)$ & $\star *$ & $2.4( \pm 0.8)$ & $2.7( \pm 0.9)$ \\
\hline Vocation & $3.2( \pm 0.7)$ & $3.3( \pm 0.7)$ & * & $3.2( \pm 0.7)$ & $3.2( \pm 0.8)$ \\
\hline Crime severity & $2.4( \pm 1.1)$ & $2.1( \pm 1.1)$ & $* *$ & $2.4( \pm 1.1)$ & $2.6( \pm 1.2)$ \\
\hline Medical problems & $2.48( \pm 0.8)$ & $1.9( \pm 0.9)$ & $* * *$ & $2.5( \pm 0.8)$ & $2.4( \pm 1.0)$ \\
\hline Index incarceration days & $242.8( \pm 309.8)$ & $148.9( \pm 312.6)$ & ** & $239.9( \pm 312.4)$ & $306.3( \pm 1109.9)$ \\
\hline Release type & & & $* * *$ & & \\
\hline Under supervision & $38(41.1)$ & $388(15.0)$ & & $38(40.9)$ & $34(36.2)$ \\
\hline Other & $56(58.9)$ & $2206(85.0)$ & & $55(59.1)$ & $60(63.3)$ \\
\hline Proportion of life spent in DOC & $42( \pm 19.9)$ & $37.7( \pm 19.0)$ & * & $41.9( \pm 20.0)$ & $41.6( \pm 19.2)$ \\
\hline \multicolumn{6}{|l|}{ Behavioural health history } \\
\hline Any inpatient, mental health & $14(14.7)$ & $103(4.0)$ & $* * *$ & $13(13.8)$ & $11(11.7)$ \\
\hline Proportion life involved with DMHAS & $17.9( \pm 15.2)$ & $12.7( \pm 11.2)$ & $* * *$ & $17.4( \pm 14.6)$ & $18.0( \pm 12.2)$ \\
\hline \multicolumn{6}{|l|}{ Medical chronic condition } \\
\hline Myocardial infarction & $5(5.3)$ & $33(1.3)$ & ** & $5(5.3)$ & $4(4.3)$ \\
\hline Dementia & $3(3.2)$ & $8(0.3)$ & *** & $3(3.2)$ & $1(1.1)$ \\
\hline Diabetes with or without complications & $20(21.1)$ & $294(11.3)$ & ** & $19(20.2)$ & $15(16.0)$ \\
\hline Moderate or severe liver disease & $5(5.3)$ & $17(0.7)$ & *** & $5(5.3)$ & $4(4.3)$ \\
\hline Other Gl conditions & $52(54.7)$ & $1116(43.0)$ & * & $51(54.4)$ & $53(56.4)$ \\
\hline Opioid abuse/dependence & $37(38.9)$ & $733(28.3)$ & * & $36(38.3)$ & $37(39.4)$ \\
\hline Alcohol abuse/dependence & $51(53.7)$ & $861(33.2)$ & *** & $50(53.2)$ & $50(53.2)$ \\
\hline Weighted CCl score & $2.0( \pm 3.0)$ & $1.25( \pm 2.1)$ & * & $2.0( \pm 3.0)$ & $2.5( \pm 3.4)$ \\
\hline Total number of chronic conditions & $1.1( \pm 1.6)$ & $0.8( \pm 1.2)$ & ** & $1.1( \pm 1.6)$ & $1.3( \pm 1.7)$ \\
\hline
\end{tabular}

Boldface indicates statistical significance $\left({ }^{*} \mathrm{p} \leq 0.05,{ }^{* *} \mathrm{p} \leq 0.01,{ }^{* *} \mathrm{p} \leq 0.0001\right.$

†One TCN case was excluded from the analysis since no matching case could be identified.

$\mathrm{CCl}$, Charlson Comorbidity Index; DMHAS, Department of Mental Health and Addiction Services; DOC, Department of Correction; GI, gastrointestinal; TCN, Transitions Clinic Network.

comparison group. There were no differences in the rate of imprisonment, arrests or new convictions between the TCN and comparison group. The TCN group had fewer parole or probation technical violation (17\% vs $33 \%$, $\mathrm{p}<0.05)$ compared with the control group. The TCN group, on average, spent fewer days reincarcerated (101 vs 187 days, $\mathrm{p}<0.001)$ compared with the comparison group. The percentage of participants in either arm who 
Table 2 Criminal justice contact and preventable healthcare utilisation within 12 months

$\begin{array}{lll}\text { TCN }(n=94) & \text { Controls }(n=94) & \begin{array}{l}\text { Mean or percentage } \\ \text { difference }(95 \%) \text { or })\end{array}\end{array}$

\begin{tabular}{|c|c|c|c|c|}
\hline \multicolumn{5}{|l|}{ Incarceration } \\
\hline Any arrest & $22(23.4)$ & $14(14.9)$ & 8.5 (-2.8 to 19.6$)$ & \\
\hline New conviction & $3(3.2)$ & $8(8.5)$ & $-5.3(-13.0$ to 1.8$)$ & \\
\hline $\begin{array}{l}\text { Days incarcerated } \\
\text { (among those who are reincarcerated) }\end{array}$ & 101.1 & 187.4 & $-86.3(-136.3$ to -36.4$)$ & *** \\
\hline $\begin{array}{l}\text { Inpatient days (among those who are } \\
\text { hospitalised) }\end{array}$ & 12.3 & 24.7 & $-12.4(-49.9$ to 23.1$)$ & \\
\hline Inpatient episodes & 2.9 & 4.3 & $-1.4(-8.0$ to 5.2$)$ & \\
\hline \multicolumn{5}{|l|}{ Preventable ED visits } \\
\hline
\end{tabular}

Boldface indicates statistical significance $\left({ }^{*} \mathrm{p} \leq 0.05,{ }^{* *} \mathrm{p} \leq 0.0001\right)$.

ED, emergency department; TCN, Transitions Clinic Network.

had any preventable hospitalisations and ED visits was similar.

In the zero-inflation component of the ZINB model, after adjusting for inpatient days, the odds of reincarceration or rearrest were similar for both groups (table 3). In logistic regression models, being in the TCN group was associated with a $62 \%$ decrease in the odds of returning to incarceration for parole or probation violations compared with the control group (adjusted $\mathrm{OR}=0.38$; $95 \%$ CI 0.16 to 0.93$)$. The number of days spent incarcerated was also significantly less for individuals seen in the TCN programme compared with the matched controls (adjusted incidence rate ratio [IRR] $=0.55 ; 95 \%$ CI 0.35 to 0.84 ), after adjusting for hospitalisation days.

Among those who had been hospitalised, and after adjusting for incarceration days, the TCN group had significantly fewer episodes of preventable hospitalisations (IRR $=0.46 ; 95 \%$ CI 0.24 to 0.89$)$ and shorter length of hospital stay (IRR $=0.41 ; 95 \%$ CI 0.35 to 0.84 ) compared with the matched comparison group. The number of preventable ED episodes was similar for both groups.

\section{DISCUSSION}

We found that participants of an enhanced primary care-based programme for individuals just released from prison spent $45 \%$ fewer days incarcerated in a correctional facility in the 12 months following release compared with the matched comparison group that was not enrolled in such a programme. So for the 94 individuals who were in the control group, more than 2300 days incarcerated would be spared if they had participated in a TCN programme. Currently, strategies for reducing the numbers of individuals incarcerated focus on public safety, criminal justice and sentencing reform, such as eliminating cash bail and mandatory sentencing and reducing parole violations (usually in the form of parole policy reform). However, expansion of enhanced primary care programmes for individuals released from prison could also be an additional strategy to reduce the correctional facility population.

TCN programmes may reduce the length of stay in a correctional facility in several ways. One possibility is that the TCN programme connects participants to inpatient and outpatient substance use treatment programmes, thus leading to decreased number of days incarcerated through an alternative sentence. Also, TCN patients, having received treatment for mental health, substance use and physical health conditions while in the community, may be less disruptive once reincarcerated or have developed a social support network, such that they are able to make bail sooner and be released. Future research should explore the mechanisms by which participation in the TCN programme is associated with decreased time reincarcerated.

We did not find any differences between arrest rates and new conviction rates. The TCN programme serves individuals who have already been incarcerated and who have had sizeable interactions with the criminal justice system previously. Reducing arrests or imprisonments may be more difficult to achieve for a primary care programme that is focused on patient health and wellbeing and not just engagement with the criminal justice system. We did find, however, that individuals who participated in the TCN programme returned to DOC less for parole or probation violations compared with those in the matched comparison group. One possible reason is 


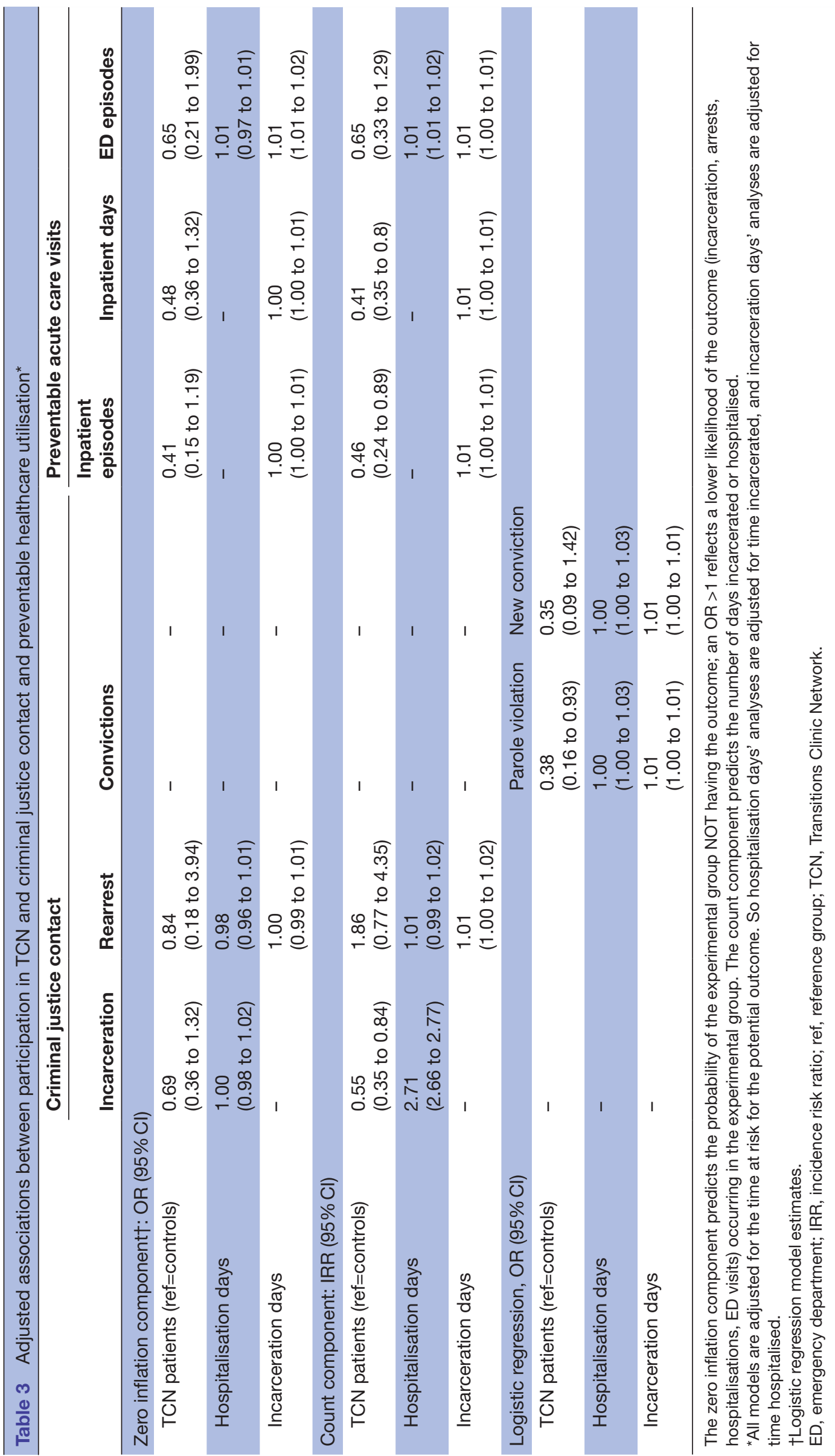


that TCN programme providers communicate regularly (when given permission by their patients) with criminal justice entities, especially parole and probation officers. These relationships may be important in identifying alternatives to reincarceration for technical violations, including enrolling patients in substance use treatment when individuals have relapsed to drug use. If we estimate that nationally there are at least 61000 individuals who are in correctional facilities for parole or probation technical violations, ${ }^{38}$ engaging them into programmes similar to the TCN in community health centres nationwide could prevent an additional 20000 incarcerations per year.

A surprising finding is that the TCN programme did not have an impact on reducing preventable ED utilisation. In a past study using randomised design in San Francisco, we found that individuals who were randomly assigned to the TCN programme in San Francisco had almost 50\% fewer all-cause ED visits compared with the group that was randomised to get expedited primary care in a safety-net primary care clinic. ${ }^{22}$ One explanation may be that the majority in the matched comparison group were still seen in primary care and thus did not have more ED visits or visits for preventable conditions.

Notably, among those who were hospitalised, individuals in the TCN programme did have fewer numbers of hospitalisations for conditions that are preventable with engagement in primary care, compared with those in the matched comparator group. One possible reason is that TCN community health workers provide significant support around medication management and adherence, chronic disease self-management, and helping patients address their housing, food insecurity and employment needs, which may reduce hospitalisations. Other studies of community health workers have found similar effects on hospital readmissions. ${ }^{39}$ Also, we found that participants of the TCN programme had almost $60 \%$ shorter lengths of hospital stay compared with the control group. TCN teams coordinated with inpatient teams to ensure smooth discharges to home and close primary care follow-up, which may account for shorter time hospitalised.

This study moves the field forward in its use of data and measurement of outcomes. It is among the first exploring how the health system can play a role in addressing incarceration as a social determinant of health. We were able to link data across a state with an integrated jail and prison system (meaning all correctional facilities fall under the authority of a single agency), so measuring criminal justice contact is more reliable and accurate. In doing so, we were able to measure days incarcerated as an important outcome, given that any time spent incarcerated can have an impact on individual health outcomes, employment and housing. In most jurisdictions, these data systems are not interconnected, so evaluations historically have been unable to determine programme impact across the full spectrum of affected services. We could achieve this given strong state agency partnerships, which enable data linkages. There is a significant need for more experimental studies that shift away from solely health system-centric outcomes such as ED visits, inpatient utilisation, and associated costs of care or reimbursements to consider outcomes which reflect service use across multiple health and social service systems, including hospitals, clinics, substance use and mental health services, and criminal justice systems, but also ambulance services, shelters and community-based agencies. Additionally, future studies should explore the impact of these programmes on those measures, as well as patient quality of life and well-being, metrics rarely used in studies of justice-involved populations, but often used to justify the use of pharmacological therapies or provision of other clinical services. A broader range of outcomes would enable us to understand the full impact of primary care-based programmes on the health of individuals just released from prison.

\section{Limitations}

A few limitations of this study should be noted. The choice of variables used in the construction of the propensity scores was limited by those measured in the administrative databases. For instance, we did not have measures of individual characteristics like housing status and social support, or individual symptomatology like depression and post-traumatic stress disorder, nor the characteristics of communities to which people return, which have been shown to be associated with future contact with the criminal justice system. Nonetheless, our propensity score did include variables most likely to be important confounders in the relationship between receipt of TCN programme and recidivism, including time incarcerated, number of comorbidities, and DOC violence and severity of crime scores. Further, the use of propensity score to identify a comparison group also limits our ability to control for possible volunteer bias of participants in TCN. While we did find that engagement in primary care (percentage of participants with two or more visits in 12 months) was equal in both arms, it is possible that individuals in TCN programme were more connected to community programmes, which was why there was less criminal justice involvement. A randomised trial would be important to conduct to bolster our findings. We followed individuals for 12 months, and many complex interventions do not show efficacy until after one or multiple years. It is possible that setting the index date on prison release for the controls and at enrolment for the TCN group would introduce bias if hospitalisations, ED visits and reincarcerations are more common immediately following release. That said, the average number of days for TCN participants between release to enrolment is about 48 days, and the majority of the control group (85\%-95\%) did not have inpatient hospitalisations, ED visits or time incarcerated until 48 days after their jail release dates. So how soon they experienced hospitalisations, ED visits and reincarcerations after release date did not seem to bias our conclusions. Lastly, we conducted this evaluation within a single and unified state system and acknowledge that our findings may not be generalisable to other state and local healthcare and criminal justice systems. 


\section{CONCLUSION}

We found that an enhanced primary care-based programme showed reductions in future contact with the criminal justice system by reducing length of time imprisoned and technical violations for individuals just released from prison. Modest investments in primary care infrastructure for programmes targeting individuals just released from prison may lead to efficiencies in healthcare utilisation, but also reduced criminal justice contact, leading to improved health overall.

\section{Author affiliations}

${ }^{1}$ Internal Medicine, Yale University School of Medicine, New Haven, Connecticut, USA

${ }^{2}$ School of Social Work, University of Connecticut System, Storrs, Connecticut, USA

${ }^{3}$ Research Division, Connecticut Department of Mental Health and Addiction Services, Hartford, Connecticut, USA

${ }^{4}$ Yale University School of Public Health, New Haven, Connecticut, USA

${ }^{5}$ Connecticut Department of Correction, Wethersfield, Connecticut, USA

${ }^{6}$ Family and Community Medicine, University of California, San Francisco, San

Francisco, California, USA

Contributors JAA, LF, HL, SS, SHB and EAW conceived and initiated the collaborative project. JAA, HL and LF were responsible for the acquisition of the data. HL performed the data analyses. JAA, HL and EAW drafted the paper. JAA, LF, HL, SS, SHB, LP, KM, EAW and CG interpreted the data, revised the paper for important intellectual content, and reviewed and approved the submitted version. EAW is the guarantor and affirms that the manuscript is an honest, accurate and transparent account of the study being reported, and that aspects of the study have not been published elsewhere.

Funding The study described was supported by the Centers for Medicare and Medicaid Services (Grant No 1CMS331071-01-00). JAA and EAW received salary support from the Bureau of Justice Assistance (Grant No 2015-RY-BX-K002). The content of this article is solely the responsibility of the authors and does not necessarily represent the official views of the Department of Health and Human Services or any of its agencies, the Connecticut Department of Correction, the Connecticut Department of Mental Health and Addiction Services, or the Bureau of Justice Assistance.

Competing interests None declared.

Patient consent for publication Not required.

Ethics approval Participants of the TCN programme in New Haven provided informed consent for participation in this study and the linkage of their data to administrative databases. The institutional review boards of Yale University School of Medicine, Connecticut DMHAS and the US Office for Human Research Protections approved this study.

Provenance and peer review Not commissioned; externally peer reviewed.

Data sharing statement Original de-identified data can be requested from $\mathrm{HL}$ after permissions are obtained from the Connecticut Department of Correction, the Department of Mental Health and Addiction Services, and the Department of Public Health.

Open access This is an open access article distributed in accordance with the Creative Commons Attribution Non Commercial (CC BY-NC 4.0) license, which permits others to distribute, remix, adapt, build upon this work non-commercially, and license their derivative works on different terms, provided the original work is properly cited, appropriate credit is given, any changes made indicated, and the use is non-commercial. See: http://creativecommons.org/licenses/by-nc/4.0/.

\section{REFERENCES}

1. Shannon SKS, Uggen C, Schnittker J, et al. The Growth, Scope, and Spatial Distribution of People With Felony Records in the United States, 1948-2010. Demography 2017;54:1795-818.

2. Wildeman $C$, Wang EA, incarceration $M$. public health, and widening inequality in the USA. The Lancet 2017;389:1464-74.

3. Hagan BO, Wang EA, Aminawung JA, et al. History of solitary confinement is associated with post-traumatic stress disorder symptoms among individuals recently released from prison. J Urban Health 2018:95:1-8.

4. Western B, Braga AA, Davis J, et al. Stress and hardship after prison. AJS 2015;120:1512-47.

5. Pager D. The mark of a criminal record. Am J Sociol 2003;108:937-75.

6. Wang EA, Zhu GA, Evans L, et al. A pilot study examining food insecurity and HIV risk behaviors among individuals recently released from prison. AIDS Educ Prev 2013;25:112-23.

7. Durose MR, Cooper AD, Snyder HN. Recidivism of prisoners released in 30 states in 2005: Patterns from 2005 to 2010. Washington, DC: US Department of Justice, Office of Justice Programs, Bureau of Justice Statistics, 2014.

8. Milloy MJ, Kerr T, Buxton J, et al. Dose-response effect of incarceration events on nonadherence to HIV antiretroviral therapy among injection drug users. J Infect Dis 2011;203:1215-21.

9. Lorvick J, Comfort M, Kral AH, et al. Exploring lifetime accumulation of criminal justice involvement and associated health and social outcomes in a community-based sample of women who use drugs. Journal of Urban Health 2017:1-10.

10. Makarios M, Steiner B, Travis LF. Examining the predictors of recidivism among men and women released from prison in Ohio. Crim Justice Behav 2010;37:1377-91.

11. Morrissey JP, Steadman HJ, Dalton KM, et al. Medicaid enrollment and mental health service use following release of jail detainees with severe mental illness. Psychiatr Serv 2006;57:809-15.

12. Morrissey JP, Cuddeback GS, Cuellar AE, et al. The role of Medicaid enrollment and outpatient service use in jail recidivism among persons with severe mental illness. Psychiatr Serv 2007;58:794-801.

13. Mallik-Kane K, Visher CA. Health and Prisoner Reentry: How Physical, Mental, and Substance Abuse Conditions Shape the Process of Reintegration. Washington DC: The Urban Institute, 2008.

14. Cuellar AE, Cheema J. As roughly 700,000 prisoners are released annually, about half will gain health coverage and care under federal laws. Health Aff 2012;31:931-8.

15. Patel K, Boutwell A, Brockmann BW, et al. Integrating correctional and community health care for formerly incarcerated people who are eligible for Medicaid. Health Aff 2014;33:468-73.

16. Schmitt J, Warner K, Gupta S. The high budgetary cost of incarceration. Washington, DC: Center for Economic and Policy Research, 2010.

17. Vogler J. Access to Health Care and Criminal Behavior: Short-Run Evidence from the ACA Medicaid Expansions, 2017.

18. Wen $\mathrm{H}$, Hockenberry JM, Cummings JR. The effect of Medicaid expansion on crime reduction: Evidence from HIFA-waiver expansions. J Public Econ 2017;154:67-94.

19. Spaulding AC, Drobeniuc A, Frew PM, et al. Jail, an unappreciated medical home: Assessing the feasibility of a strengths-based case management intervention to improve the care retention of HIV-infected persons once released from jail. PLoS One 2018;13:e0191643.

20. Wohl DA, Scheyett A, Golin CE, et al. Intensive case management before and after prison release is no more effective than comprehensive pre-release discharge planning in linking HIVinfected prisoners to care: a randomized trial. AIDS Behav 2011;15:356-64.

21. Wohl DA, Golin CE, Knight K, et al. Randomized controlled trial of an intervention to maintain suppression of HIV viremia After Prison Release: The imPACT Trial. J Acquir Immune Defic Syndr 2017;75:81-90.

22. Wang EA, Hong CS, Shavit S, et al. Engaging individuals recently released from prison into primary care: a randomized trial. Am J Public Health 2012;102:e22-e29.

23. Cheng Q, Kinner SA, Lee XJ, et al. Cost-utility analysis of lowintensity case management to increase contact with health services among ex-prisoners in Australia. BMJ Open 2018;8:e023082.

24. Kinner SA, Alati R, Longo M, et al. Low-intensity case management increases contact with primary care in recently released prisoners: a single-blinded, multisite, randomised controlled trial. J Epidemiol Community Health 2016;70:683-8.

25. Shavit S, Aminawung JA, Birnbaum N, et al. Transitions Clinic Network: Challenges And Lessons In Primary Care For People Released From Prison. Health Aff 2017;36:1006-15.

26. Rosenbaum PR, Rubin DB. The central role of the propensity score in observational studies for causal effects. Biometrika 1983;70:41-55.

27. Campbell KM, Deck D, Krupski A. Record linkage software in the public domain: a comparison of Link Plus, The Link King, and a 'basic' deterministic algorithm. Health Informatics J 2008;14:5-15.

28. Charlson ME, Pompei P, Ales KL, et al. A new method of classifying prognostic comorbidity in longitudinal studies: development and validation. J Chronic Dis 1987;40:373-83. 
29. Quan H, Li B, Couris CM, et al. Updating and validating the Charlson comorbidity index and score for risk adjustment in hospital discharge abstracts using data from 6 countries. Am J Epidemiol 2011;173:676-82.

30. Parsons L. Reducing bias in a propensity score matched-pair sample using greedy matching techniques. Proceedings of the twenty-sixth Annual SAS users group international conference: SAS Institute Inc, 2001.

31. Stuart EA. Matching methods for causal inference: A review and a look forward. Statistical Science 2010;25:1-21.

32. Coca-Perraillon M. Local and global optimal propensity score matching. SAS Global Forum; 2007:1-9.

33. Austin J, ed. The Math and Science of Decarceration: Oxford University Press, 2016.
34. AHRQ Quality Indicators - Guide to Prevention Quality Indicators: Hospital Admission for Ambulatory Care Sensitive Conditions. Rockville, MD: Agency for Healthcare Research and Quality, 2002.

35. Gill JM, Mainous AG. The role of provider continuity in preventing hospitalizations. Arch Fam Med 1998;7:352-7.

36. Hall DB. Zero-inflated Poisson and binomial regression with random effects: a case study. Biometrics 2000;56:1030-9.

37. Loeys T, Moerkerke B, De Smet O, et al. The analysis of zero-inflated count data: beyond zero-inflated Poisson regression. Br J Math Stat Psychol 2012;65:163-80.

38. Hager E. At Least 61,000 Nationwide Are in Prison for Minor Parole Violations. Marshall Project, 2017.

39. Kangovi S, Mitra N, Grande D, et al. Patient-centered community health worker intervention to improve posthospital outcomes: a randomized clinical trial. JAMA Intern Med 2014;174:535-43. 